\title{
A NEW SPECIES OF LEPIDOPRIA FROM NORTH AMERICA.
}

\author{
By Charles T. Brues, \\ Bussey Institution, Harvard University.
}

I received recently from Mr. J. J. Davis of the Bureau of Entomology a very interesting Diapriid parasite of the genus Lepidopria which was reared by Mr. J. A. Hyslop from a Dipterous puparium found in an adult June-beetle. According to Mr. Davis the puparium was probably Cryptomeigenia theutis. The Diapriid is thus a secondary parasite of the June-beetle, but actually lives in the Cryptomeigenia which is in accordance with the known habits of the other members of the family which have been reared from various Diptera. This is the first Lepidopria to be found in the Western Hemisphere as the only species hitherto described, L. pedestris Kieffer, was found in Italy. ${ }^{1}$

From the form of the body which is exceeding ant-like, one might be led to suppose that the members of Lepidopria like those of the related Solenopsia are myrmecophilous, but such is evidently not the case, at least with the present species. Although there are quite considerable differences between the European and North American species I think that both can, at least for the present, be considered congeneric. The most striking disparity appears in the form of the antennæ, but as these organs are very highly modified in the closely related Solenopsia one cannot reasonably place very great weight upon them as generic characters.

Following is a description of the new form:

\section{Lepidoria aberrans sp. nov.}

ㅇ. Length. Piceous, the thorax and base of the abdomen fuscous; legs and antennæ yellow. Antennæ 12-jointed, stout; scape arcuate, as long as the pedicel and first four joints of the flagellum together; pedicel one-half longer than broad, tip as wide as the apex of the scape; first joint of flagellum two-thirds as long as the pedicel and much narrower; second to seventh joints of flagellum short and broad, strongly transverse; club three-jointed,

1 André, Hymén. Europe et Algérie, Vol. 10, p. 869. (1911). 
a little longer than the preceding joints of the flagellum taken together. Eyes very small, less than half as long as the cheeks; ocelli large, in an equilateral triangle. Palpi very short, scarcely projecting from the mouth opening, the maxillary apparently with three very short joints and the labial with a single joint. Metathorax clothed with woolly hairs, its upper surface slightly raised behind;

the posterior surface excavated to receive the convex base of the nodiform first abdominal segment, the latter elevated into a large erect scale-like node which is curved backward so that its anterior surface is convex and the posterior one concave, its surface woolly. Second

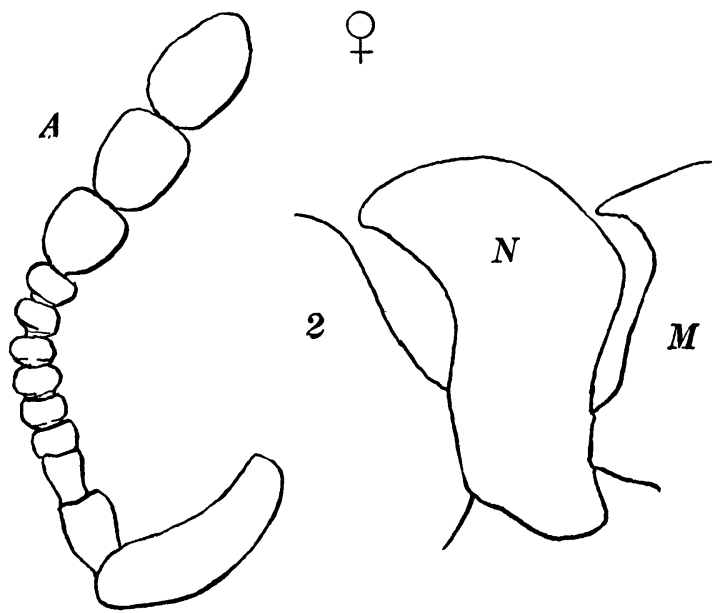

Fig. 1. Lepidopria aberrans sp. nov. ․ A, antenna; $N$, lateral view of petiole of abdomen shown in position between the metathorax $(M)$ and the second abdominal segment (2).

segment comprising over two-thirds of the abdomen, following segments very short. Legs stout, tibiæ, especially the anterior ones, strongly swollen apically; tarsal claws stout, simple.

Described from one female, mounted in balsam, reared as mentioned above from a Tachinid pupa, probably Cryptomeigenia theutis, found in an adult Phyllophaga (Lachnosterna) inversa at Hagerstown, Md., August 15, 1913.

This species differs from $L$. pedestris Kieff. by the three-jointed antennal club. 

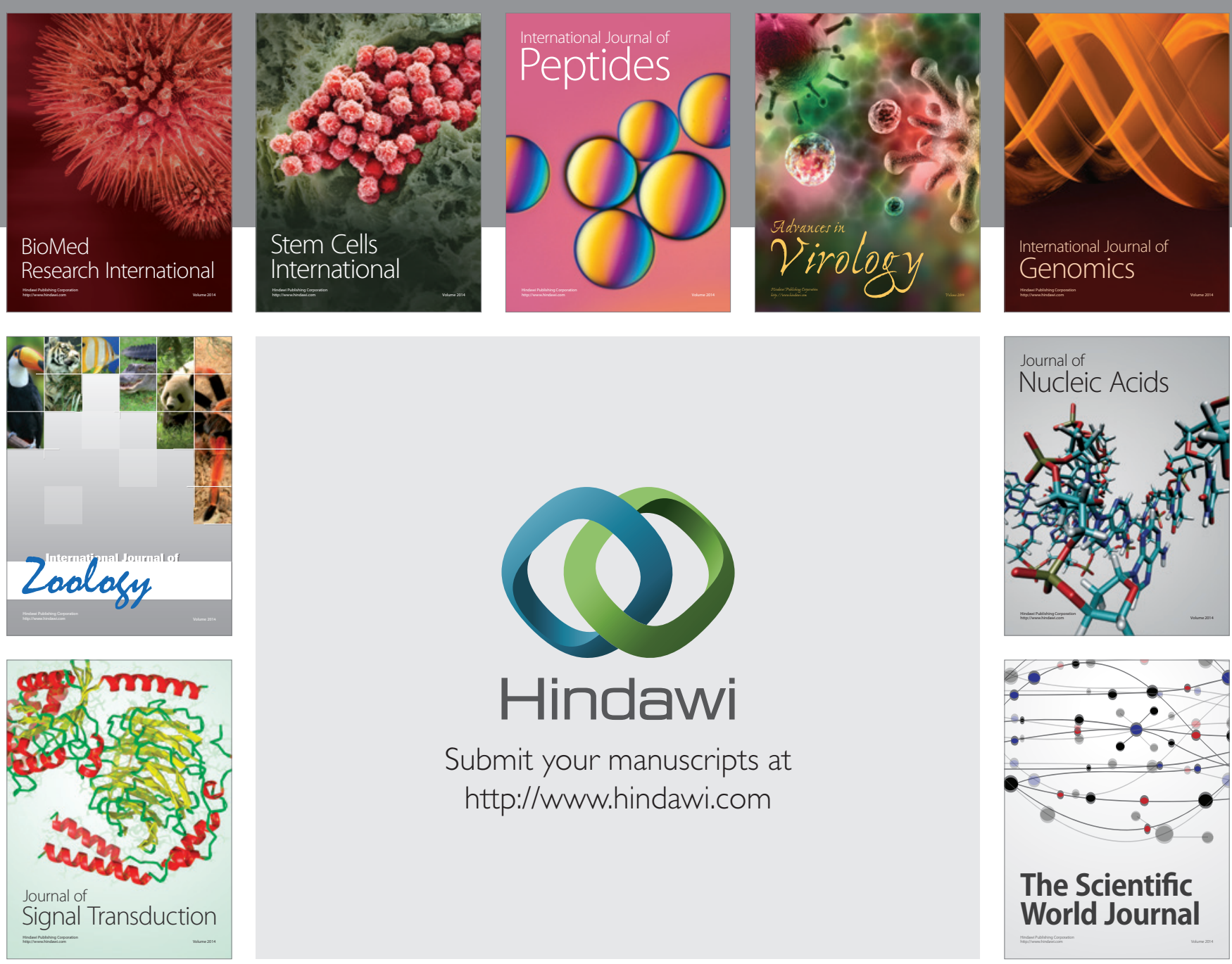

Submit your manuscripts at

http://www.hindawi.com
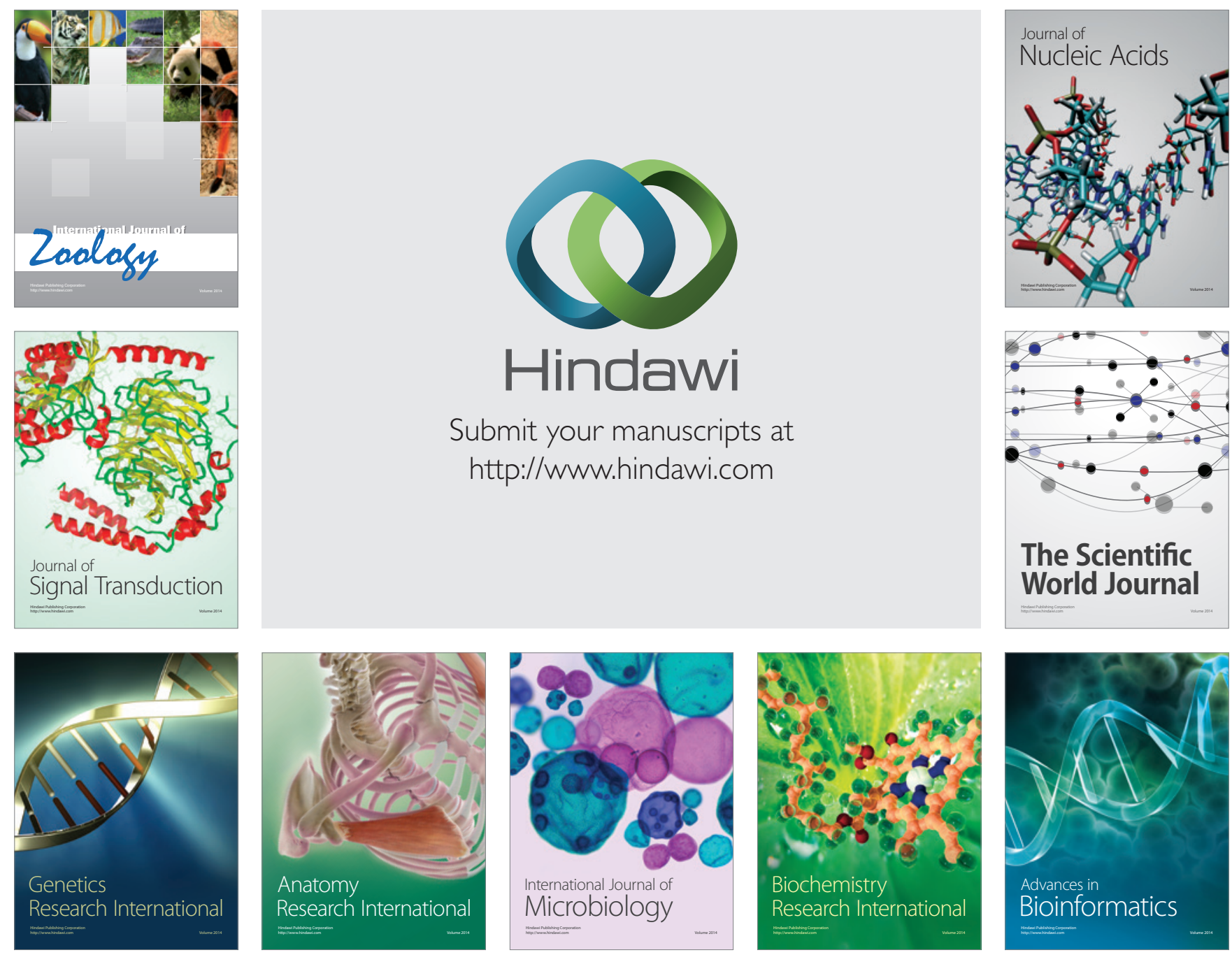

The Scientific World Journal
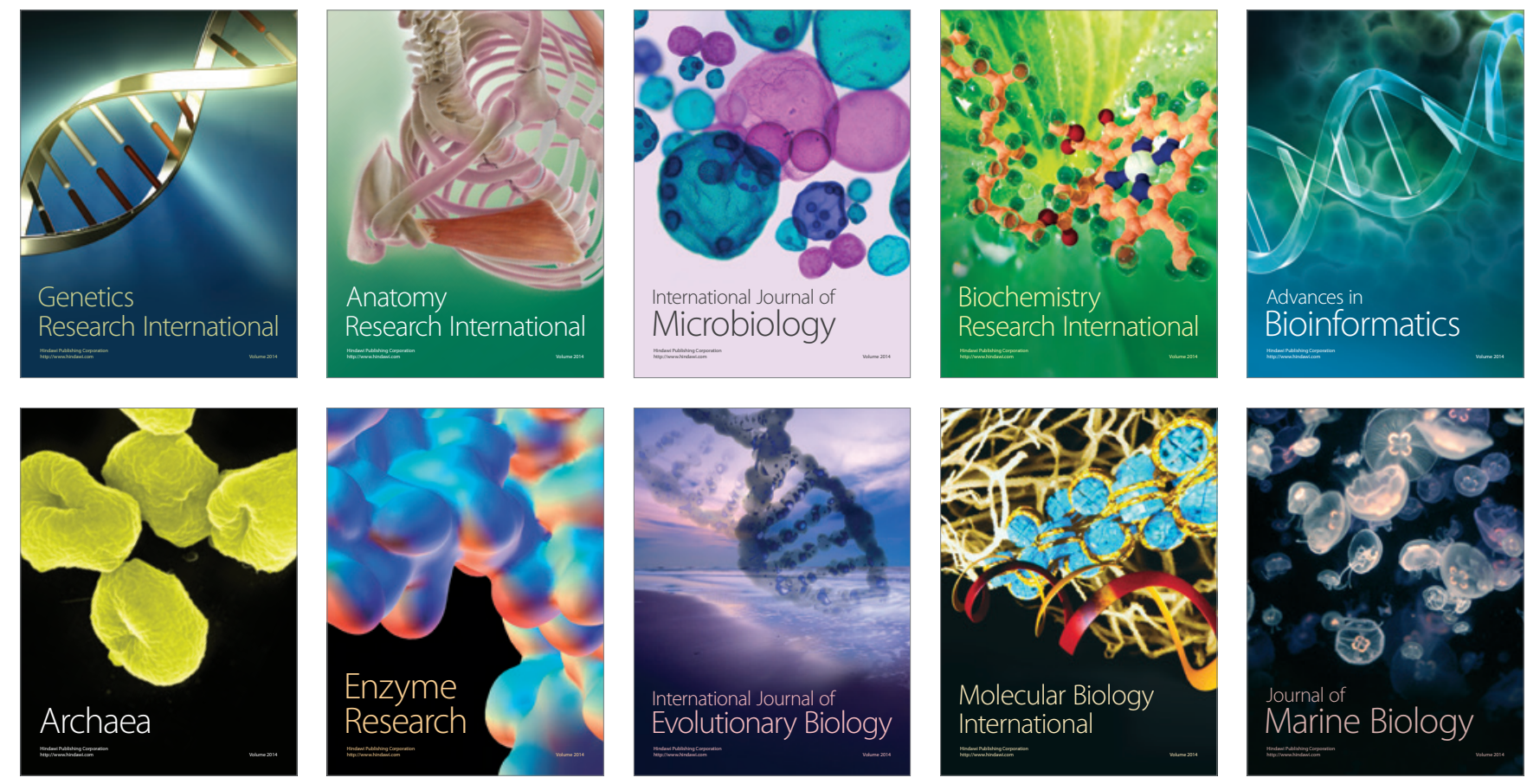